\title{
O USO DO PORTFÓLIO NA FORMAÇÃO EM FONOAUDIOLOGIA SOB O EIXO DA INTEGRALIDADE
}

\section{The use of portfolio in Speech and Language Pathology undergraduate education from the perspective of comprehensive training}

\author{
Regina Yu Shon Chun ${ }^{(1)}$, Mariana Mendes Bahia ${ }^{(2)}$
}

\begin{abstract}
RESUMO
Objetivos: investigar o portfólio como instrumento de avaliação e aprendizagem em um Curso de Fonoaudiologia e verificar as expectativas e conhecimento acerca da Fonoaudiologia. Métodos: pesquisa retrospectiva de abordagem qualitativa e quantitativa, aprovada pelo Comitê de Ética em Pesquisa, corpus de 24 sujeitos, do $1^{\circ}$ ano do curso de graduação em Fonoaudiologia que cursaram a disciplina História da Fonoaudiologia. A coleta de dados ocorreu por meio de portfólios e depoimentos escritos dos sujeitos. Foram aceitas mais de uma resposta nas categorias de análise. Para análise estatística foram utilizados os Testes Exato de Fischer e Qui-Quadrado. Resultados: os portfólios evidenciam quanto à visão inicial da Fonoaudiologia que $53 \%$ dos sujeitos $(n=15)$ indicaram conhecer a profissão por contato anterior e $40 \%$ referiram pouco conhecimento da profissão ao ingressar no Curso. $71 \%$ dos sujeitos $(n=24)$ apontaram o ajudar/lidar com as pessoas como uma das principais razões da escolha da Fonoaudiologia. Quanto aos depoimentos escritos, $71 \%(n=24)$ dos sujeitos referiram que o portfólio possibilitou reflexão e $50 \%$ que foi um meio de aquisição de conhecimento quanto à contribuição do portfólio. Conclusão: os achados mostram que o portfólio se constitui como importante instrumento processual e reflexivo. Verificam-se mudanças no decorrer da disciplina, em relação às expectativas iniciais e ao conhecimento dos sujeitos acerca da Fonoaudiologia. Contribui para a definição da escolha da profissão, em alguns casos, e favorece a percepção acerca do papel das demais disciplinas, angústias comuns entre os alunos, nessa época da graduação.
\end{abstract}

DESCRITORES: Educação Superior; Patologia da Fala e Linguagem; Avaliação

\section{INTRODUÇÃO}

Há uma exigência cada vez maior para formação de profissionais qualificados com características como criatividade, interdisciplinaridade e compromisso social ${ }^{1}$. Para isso é necessária uma prática que envolva características teóricas e práticas e que possibilite uma avaliação que enriqueça o aprendizado do aluno ${ }^{2}$.

(1) Fonoaudióloga; Docente do Curso de Graduação em Fonoaudiologia e do Mestrado Profissional Saúde, Interdisciplinaridade e Reabilitação da Universidade Estadual de Campinas, UNICAMP, Campinas, SP; Doutora em Linguística Aplicada em Estudos da Linguagem pela Pontifícia Universidade Católica de São Paulo; Pós-Doutorado em Linguística pelo Instituto de Estudos da Linguagem da Universidade Estadual de Campinas.

(2) Aluna do Curso de Graduação em Fonoaudiologia da Universidade Estadual de Campinas, UNICAMP, Campinas, SP.

Conflito de interesse: inexistente
Ademais, a formação de profissionais da área de saúde busca características para uma atuação de qualidade e voltada às necessidades sociais ${ }^{3}$. Nesse sentido, diversas ações vêm sendo realizadas com o intuito de promover mudanças na formação em saúde e melhoria no ensino e formar profissionais críticos, reflexivos e comprometidos socialmente com vistas à integralidade na atenção à saúde ${ }^{4}$.

Tal preocupação encontra-se expressa, por exemplo, na Constituição Nacional, nos documentos das Conferências Nacionais e Internacionais de Saúde, na Norma Operacional Básica sobre Recursos Humanos do SUS (NOB/RH-SUS), originária do Conselho Nacional de Saúde e consolidada pela $11^{\text {a }}$ Conferência Nacional de Saúde, dentre outras iniciativas, do Departamento de Gestão de Educação na Saúde - Ministério da Saúde, como os antigos Pólos de Educação Permanente ${ }^{5}$. 
Nesse âmbito, a Fonoaudiologia tem participado de fóruns como o FNEPAS - Fórum Nacional de Educação das Profissões na Área de Saúde - além de ter sido a área pioneira, dentre as profissões de saúde, a realizar as "Oficinas de Sensibilização Docente e Discente de Fonoaudiologia para o Sistema Único de Saúde", promovida pela Sociedade Brasileira de Fonoaudiologia (SBFa) ${ }^{6} \mathrm{com}$ apoio do Ministério da Saúde e da Organização Pan-Americana de Saúde. Tem tido participação ativa nas oficinas coletivas promovidas pelo FNEPAS em sequência às oficinas por categoria profissional em diversas regiões do país.

Deste modo, considerando-se esse contexto de articulação entre educação, ações de saúde e práticas de humanização, eixo norteador do ensino e da formação de profissionais, e buscando-se formas processuais de avaliação foi proposto em um Curso de Fonoaudiologia do interior do estado de São Paulo, o portfólio como meio reflexivo de avaliação e de aprendizagem. Trata-se do conjunto de produções de um curso ou disciplina, podendo incluir a história dos alunos, relatórios de pesquisa, reflexões de trabalhos, expectativas do curso e da profissão, auto-reflexão e auto-avaliação ${ }^{7-9}$.

Vários autores ${ }^{7,10}$ apontam que o foco do portfólio é a habilidade reflexiva, a qual favorece o aprendizado efetivo das experiências vivenciadas. A autoavaliação é importante na formação do educando, pois tem a finalidade de levá-lo a refletir sobre a sua aprendizagem e seu desenvolvimento ${ }^{11}$.

A Universidade em que foi realizada esta pesquisa tem como missão a criação e a disseminação de conhecimentos por meio da tríade ensino/pesquisa/extensão e formação de profissionais éticos, com responsabilidade social e valorização do ser humano ${ }^{12}$. O portfólio representa importante contribuição nesse sentido por incentivar a formação de profissionais reflexivos. Por sua vez, a reflexão gera processos criativos e solidários que possam assegurar o bem-estar dos indivíduos, nos termos de Ayres ${ }^{13}$ e Buss ${ }^{14}$ sobre promoção da saúde e qualidade de vida.

O objetivo dessa pesquisa, portanto, é investigar o uso do portfólio como instrumento de avaliação e de aprendizagem na disciplina História da Fonoaudiologia em um Curso de Fonoaudiologia do interior de São Paulo e verificar a compreensão e expectativas que o aluno tem acerca da Fonoaudiologia.

\section{MÉTODOS}

Trata-se de pesquisa retrospectiva de abordagem qualitativa e quantitativa, cujo corpus se constitui de 24 sujeitos, alunos de primeiro ano de um Curso de Fonoaudiologia do interior de São Paulo, que construíram o portfólio como parte integrante do processo avaliativo e de aprendizagem da disciplina História da Fonoaudiologia.

Os critérios de inclusão dos sujeitos foram alunos regulares que cursaram a disciplina História da Fonoaudiologia, construíram o portfólio como parte das atividades e concordaram em participar livremente da pesquisa por meio da assinatura do Termo de Consentimento Livre e Esclarecido, nos termos da Resolução 196/96 do CONEP. Dois alunos especiais que cursaram a disciplina foram excluídos da pesquisa.

A coleta de dados ocorreu por meio de dados dos portfólios e dos depoimentos escritos acerca das impressões dos sujeitos sobre o processo de construção do portfólio, que resultaram na constituição de um banco de dados.

O portfólio construído na disciplina História da Fonoaudiologia constituiu-se de quatro partes, de acordo com proposta da docente responsável, a saber: a) aldeia - história pessoal do aluno e as razões que o levou a escolher a fonoaudiologia como profissão; b) trajetória - percurso do aluno na disciplina: trabalhos, textos, seminários, comentários e reflexão dos temas discutidos em sala de aula; c) projetos futuros - expectativas e planejamentos relacionados ao curso e à profissão e d) arquivo materiais extras pesquisados pelos alunos.

Após leituras flutuantes do material coletado, ou seja, pré-análise para que se conhecessem os dados e que os aspectos salientes para os pesquisadores fossem destacados, foram estabelecidas as categorias de análise por meio dos critérios de repetição, aquilo que cada sujeito escreveu em comum com os outros, e de relevância, dados considerados significativos de conteúdo para os objetivos da pesquisa.

Foram estabelecidas nove categorias de análise para os portfólios, sendo que aqui serão apresentadas aquelas que evidenciam a visão inicial dos sujeitos acerca do Curso de Fonoaudiologia, no início e ao final da disciplina, e as razões da escolha da Fonoaudiologia como profissão. Para os depoimentos escritos estabelecerem-se três categorias de análise, sendo que neste artigo, apresentam-se os resultados relativos à contribuição do portfólio como forma processual e reflexiva de avaliação.

A pesquisa foi aprovada sob oㅡ 494/2006 pelo Comitê de Ética em Pesquisa da Universidade em que se realizou o estudo.

Para os tratamentos quantitativo e estatístico dos dados utilizou-se o programa Statistical Package of Social Sciences (SPSS), na versão 15. Para análise da associação entre duas variáveis categóricas foram utilizados o Teste Exato de Fisher e o Teste do Qui-Quadrado, ambos com nível de significância de $0,05(p=0,05)$. 


\section{RESULTADOS}

Dos 24 sujeitos participantes da pesquisa, 13 alunos (54\%) escolheram o Curso de Fonoaudiologia em primeira opção no vestibular e 11 (46\%) apresentaram outras opções de curso.

A visão inicial dos sujeitos $(n=15)$ acerca da Fonoaudiologia encontra-se na Figura 1.

$\mathrm{Na}$ associação das variáveis dessa categoria com a opção no vestibular, não se encontrou significância estatística.

As principais mudanças no decorrer da disciplina, verificadas pelos portfólio, são ilustradas por trechos de depoimentos dos Sujeitos 23 e 11, respectivamente:

"Quando pensei em prestar Fonoaudiologia não tinha noção de quão vasto é o campo de trabalho de uma fonoaudióloga, (...) e isso foi uma das razões que mais me deixou fascinada e acabou com a minha dúvida em relação se estava na profissão certa" (S23)

"Notamos também que nessa profissão trabaIhar em conjunto com outros profissionais pode fazer toda a diferença" (S11)

As razões da escolha da Fonoaudiologia $(n=24)$ encontram-se na Figura 2.

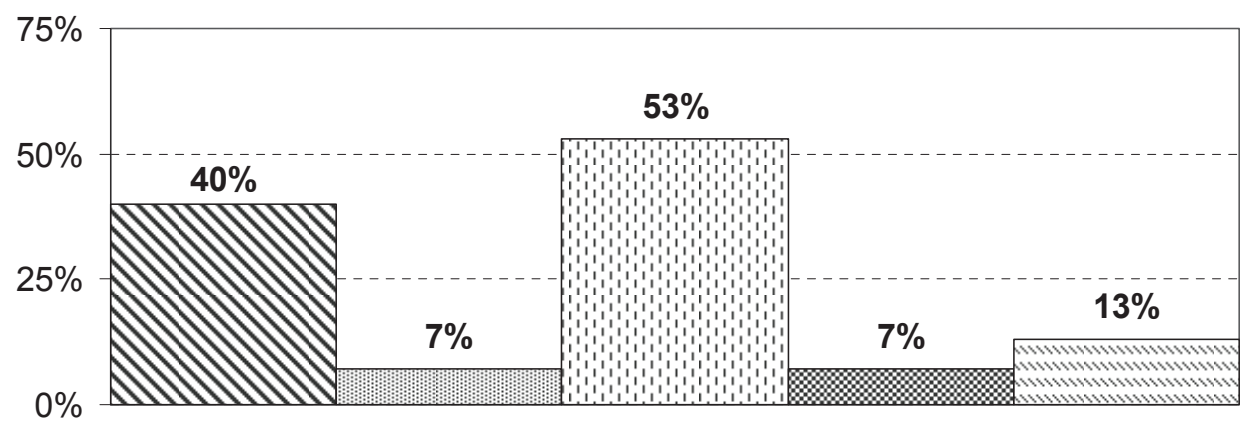

\begin{tabular}{|c|}
\hline$\triangle$ Pouco conhecimento \\
\hline 国 Atuação isolada \\
\hline Conhece por contato anterior com profissionais \\
\hline 冈 Atuação com questões sociais \\
\hline Atuação com pacientes \\
\hline
\end{tabular}

Figura 1 - Distribuição da visão inicial dos sujeitos acerca da Fonoaudiologia, segundo os portfólios

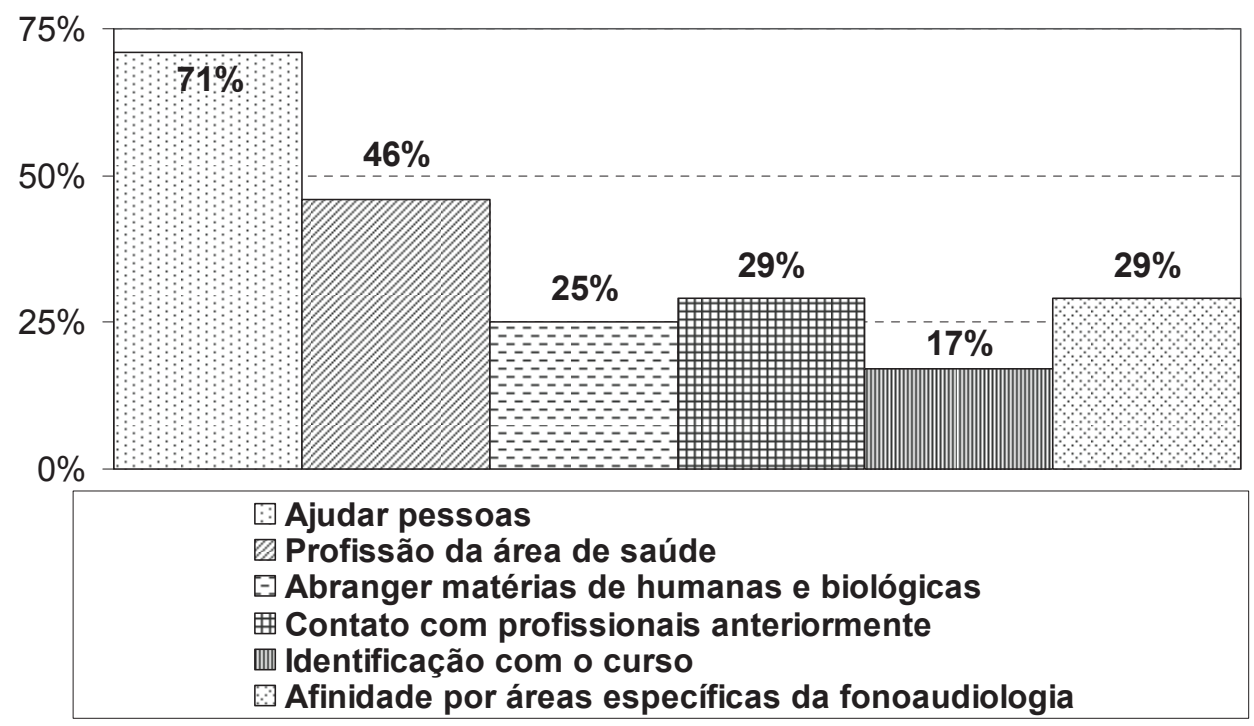

Figura 2 - Distribuição das razões da escolha por Fonoaudiologia, segundo os portfólios 


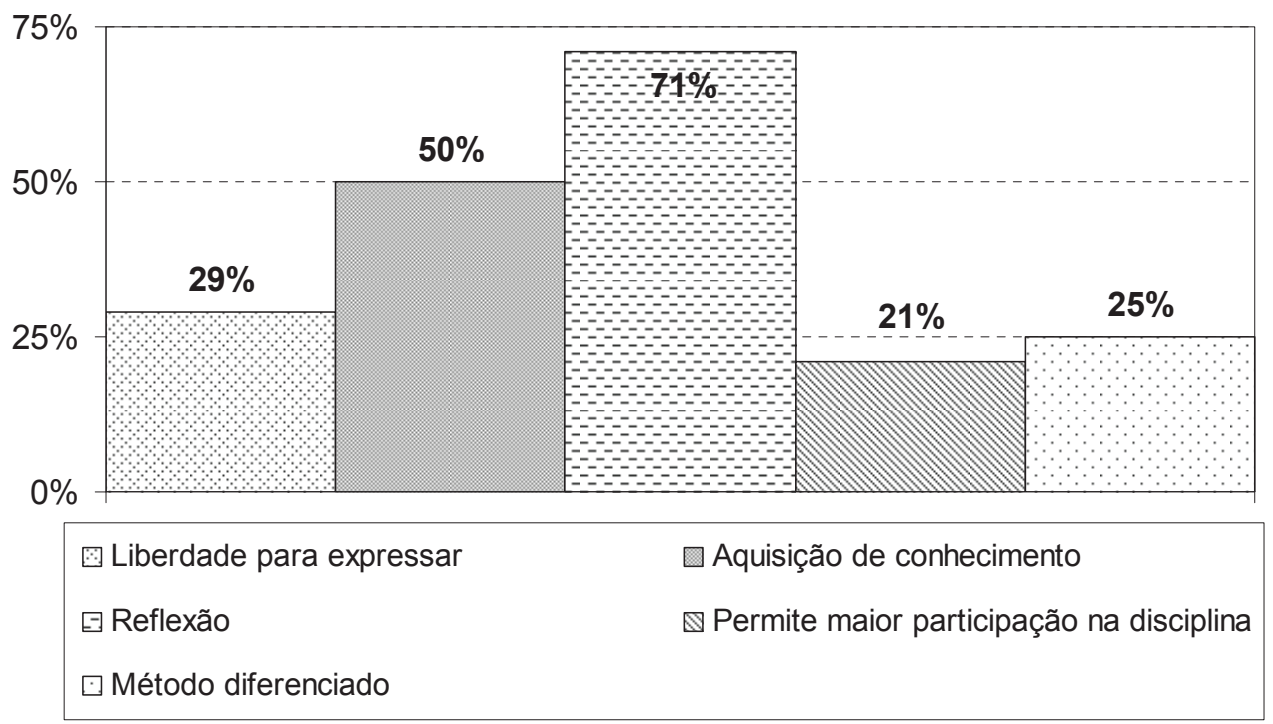

Figura 3 - Depoimentos dos sujeitos sobre a contribuição do portfólio como forma de avaliação

Os principais motivos para a escolha da Fonoaudiologia são ilustrados pelos relatos que se seguem:

"Escolhi fonoaudiologia porque adoro a área de saúde, (...) e de relacionar com pessoas e poder ajudar na reabilitação delas" (S18)

"Porque quando utilizei aparelhos ortodônticos fiz um trabalho com uma fonoaudióloga para que minha respiração e modo de utilizar a língua melhorassem" (S10)

A contribuição do portfólio como forma de avaliação verificada nos depoimentos dos sujeitos $(n=24)$ está expressa na Figura 3.

Seguem exemplos de depoimentos acerca da contribuição do portfólio:

"O portfólio é um bom instrumento de reflexão. Pudemos, através de nossos textos, refletir, pensar sobre os diferentes seminários e palestras. (...) Além disso, acredito que com a elaboração do portfólio, refletimos também sobre nossas próprias vidas" (S3)

"Achei legal poder conhecer melhor as áreas da fono e poder refletir e comentar sobre elas, mas o melhor foi ter um retorno sobre as minhas reflexões (comentários da professora), o que não aconteceria em uma prova" (S4)

"Achei interessante a construção do portfólio porque é um método que da liberdade para a pessoa pesquisar e conhecer assuntos que mais the despertaram interesse" (S5)

A associação das variáveis dessa categoria com os grupos de opção de curso no vestibular não apresentou significância estatística.

\section{DISCUSSÃO}

Os resultados dos portfólios mostram mudanças no decorrer da disciplina quanto à compreensão e expectativas relacionadas ao curso e à profissão e a contribuição do portfólio como instrumento processual e reflexivo, sendo que não foram encontrados estudos sobre seu uso na Fonoaudiologia.

As mudanças dos sujeitos, sobretudo àquelas relacionadas às áreas de atuação da Fonoaudiologia e ao trabalho interdisciplinar, evidenciam que os objetivos previstos no plano dessa disciplina, tais como propiciar uma visão geral das áreas de atuação da fonoaudiologia, suas inter-relações com outras profissões e o papel social do fonoaudiólogo, foram alcançados e facilitados pelo portfólio.

Uma das razões principais quanto à escolha da Fonoaudiologia - o ajudar pessoas - coincide com os achados em outra pesquisa ${ }^{15}$, em que a maioria dos alunos estudados relatou "o desejo de cuidar de pessoas, ajudar pessoas".

Os resultados relativos à opção no vestibular indicando a escolha por outros cursos $(n=11)$ como Medicina, Nutrição, Biologia, Psicologia e Direito também coincide com resultados dessa autora ${ }^{15}$. Em seu estudo, a opção pela Fonoaudiologia se deu pela aproximação com áreas como: Medicina, Fisioterapia, Nutrição, Odontologia, Psicologia, Letras e outras.

Observa-se que os cursos de interesse dos alunos estudados situam-se nas áreas de biológicas e humanas, sendo esta uma das justificativas de escolha da fonoaudiologia: ter matérias de biológicas e humanas. $O$ contato com a profissão/profissionais anteriormente ao ingresso no curso foi um 
fator importante para a escolha da profissão, resultado também coincidente com essa autora ${ }^{15}$.

Os resultados da contribuição do portfólio como forma de avaliação foram similares a outro estudo ${ }^{16}$ que o apontaram como importante instrumento de reflexão. Resultados semelhantes foram encontrados em pesquisas na Europa, cujos sujeitos mencionaram ter aprendido a pensar criticamente e a refletir a partir da experiência com o portfólio ${ }^{17}$. No estudo desses autores, os professores referiram que o instrumento proporcionou aumento do desenvolvimento da habilidade reflexiva e melhora no desempenho profissional dos estudantes de medicina ${ }^{18}$.

O processo de reflexão é apontado por diversos autores ${ }^{7,10,18,19}$ como o principal componente do portfólio e meio para o desenvolvimento e crescimento profissional.

Os achados mostram ainda que os sujeitos avaliaram o portfólio como método diferenciado por ser um recurso que possibilita um retorno de suas reflexões e comentários pelo professor, considerando as atividades desenvolvidas no cotidiano e a busca de conteúdos extras aula, além de permitir ao aluno desenvolver uma visão crítica e comprometida com os problemas sociais. Achados similares foram encontrados por outros pesquisadores ${ }^{19-21}$ que referiram a importância do docente dar retorno acerca dos conhecimentos adquiridos pelo aluno e daqueles que ele ainda está construindo, pois isso o auxilia no processo de construção do portfólio, além de estimular seu desenvolvimento e auto-estima.

Outros estudos ${ }^{19,21}$ indicam que o portfólio permite ao aluno maior autonomia em sua construção e em seu processo de aprendizagem, o que facilita seu desenvolvimento e permite que busque materiais de seu interesse, além de ajudá-lo no desenvolvimento do pensamento crítico.

Verifica-se, portanto, que o estudo contribui para a reflexão sobre metodologias de ensino e processos de avaliação, evidenciando a necessidade de mais pesquisas sobre o tema no âmbito da Fonoaudiologia.

\section{CONCLUSÃO}

Os achados, de modo geral, mostram que o portfólio, na perspectiva da integralidade na formação, constitui-se como um instrumento reflexivo de avaliação e de aprendizagem. Verifica-se que a introdução dessa prática, na disciplina estudada, contribui para promover diversas mudanças e reflexões do educando no decorrer da mesma, em relação a aspectos como expectativas iniciais e o conhecimento acerca da Fonoaudiologia. Além disso, contribui para da definição da escolha pelo Curso, em alguns casos, bem como favorece a percepção acerca do papel das demais disciplinas, angústias comuns entre os alunos, nessa época de ingresso na graduação.

Os resultados evidenciam este instrumento como estratégia que favorece a reflexão e a aquisição do conhecimento de modo processual e desperta a criatividade nos sujeitos tendo a integralidade como eixo norteador na formação. Portanto, o portfólio revela-se como importante ferramenta para a construção progressiva do conhecimento e de uma visão crítica e comprometida socialmente da profissão e da realidade bem como para o desenvolvimento de práticas educativas em uma perspectiva de atenção integral à saúde e qualidade de vida das populações atendidas no âmbito da Fonoaudiologia.

\section{AGRADECIMENTOS}

Agradecemos à Fundação de Amparo a Pesquisa do Estado de São Paulo pelo auxílio recebido e aos sujeitos da pesquisa pela participação no estudo. 


\section{ABSTRACT}

Purpose: to study the portfolio as a reflective tool for assessment and learning in a Speech and Language Pathology Course (SLP) and to investigate what the students expect and know about SPL field. Methods: a retrospective study that is both qualitative and quantitative and approved by the Ethics in Research Commission. There were 24 participants who were first year students of a university level (SLP) and who were enrolled in a SLP History course. Data were collected using portfolios and reports written by the participants. More than one answer per category of analysis was acceptable. Statistical analysis was done with the Fischer's Exact Test and Chi-Square. Results: as for the initial views of the SLP field, the portfolios show that $53 \%$ of the subjects $(n=15)$ reported that they knew about the profession from earlier contact, while $40 \%$ reported little knowledge of the profession before registration. Due to the written reports, $71 \%$ of the subjects $(n=24)$ indicated that the portfolios promote reflections and $50 \%$ indicate the contribution of the portfolio as a mean of acquisition of knowledge. Conclusion: the findings demonstrate the portfolio as an important tool in an ongoing reflective evaluation. There were changes about the initial impressions the undergraduates brought with them, as to their expectations and knowledge on SLP. This instrument contributes for defining the choice of profession, in some cases, and encourages the perception about the role of other disciplines, common doubts among students at this graduation period.

KEYWORDS: Education, Higher; Speech-Language Pathology; Evaluation

\section{REFERÊNCIAS}

1. Moraes RCC. Universidade hoje: ensino, pesquisa, extensão. Educ Soc. 1998 Ago; 19(63):19-37.

2. Albertino FMF, Souza NA. Avaliação da aprendizagem: o portfólio como auxiliar na construção de um profissional reflexivo. Est Aval Educ. 2004 Jun; (29):169-89.

3. Ceccim RB, Feuerwerker LCM. O quadrilátero da formação para a área da saúde: ensino, gestão, atenção e controle social. Physis. 2004; 14(1):4165.

4. Ceccim RB, Feuerwerker LCM. Mudanças na graduação das profissões de saúde sob o eixo da integralidade. Cad Saúde Pública. 2004 Out; 20(5):1400-10.

5. Chun RYS. Proposta de ativação de mudanças em um Curso de Fonoaudiologia do interior de São Paulo. [monografia] Rio de Janeiro (RJ): Escola Nacional de Saúde Pública Sérgio Arouca da Fundação Oswaldo Cruz; 2007.

6. Sociedade Brasileira de Fonoaudiologia. Relatório Final das Oficinas. Disponível em: http://www.sbfa. org.br/RelatFinalOficinasSUS.pdf. Acesso em 02 fev 2008.

7. Rees C. The use (and abuse) of the term 'portfolio'. Med Educ. 2005 Apr; 39(4):436.

8. Cole G. The definition of 'portfolio'. Med Educ. 2005 Nov; 39(11):1141.

9. Rees C. 'Portfolio' definitions: we need a wider debate? Med Educ. 2005 Nov; 39(11):1142.
10. Driessen EW, Overeem K, van Tartwijk J, van der Vleuten CPM, Muijtjens AMM. Validity of portfolio assessment: which qualities determine ratings? Med Educ. 2006 Sep; 40(9):862-6.

11. Rossetto EG, Kikuchi EM, Lima JVC, Guariente MHDM, Takahashi OC, Hirazawa SA. Avaliação do processo de ensino e aprendizagem. In: Dellaroza MSG, Vannuchi MTO. O currículo integrado do Curso de Enfermagem da Universidade Estadual de Londrina: do sonho à realidade. São Paulo: Hucitec; 2005. p. 59-84.

12. Planes - Universidade Estadual de Campinas. Planejamento estratégico. Gestão 2005-2009. Disponível em: ‘www.cgu.unicamp.br/pei〉. Acesso em: 01 ago 2008.

13. Ayres JR. Norma e formação: horizontes filosóficos para as práticas de avaliação no contexto da promoção da saúde. Ciênc Saúde Coletiva. 2004; 9(3):583-92.

14. Buss PM. Promoção da saúde e qualidade de vida. Ciênc Saúde Coletiva. 2000; 5(1):163-77.

15. Martins MCFN. A transição estudantefonoaudiólogo: estudo qualitativo sobre a vivencia dos primeiros atendimentos [tese]. São Paulo (SP): Universidade Federal de São Paulo; 1998.

16. Pernigotti JM, Saenger L, Goulart LB, Avila VMZ. O portfólio pode muito mais do que uma prova. Pátio Rev Pedag. 2000 Fev-Abr; 4(12):54-6.

17. Simão AMV, Flores MA. O aluno universitário: aprender a auto-regular a aprendizagem sustentada por dispositivos participativos. Ciênc Letras. 2006 Jul-Dez; (40):252-70. 
18. Driessen EW, van Tartwijk J, Overreem K, Vermunt JD, van der Vleuten CPM. Conditions for successful reflective use of portfolios in undergraduate medical education. Med Educ. 2005; 39(12):1230-5.

19. Harris S, Dolan G, Fairbairn G. Reflecting on the use of student portfolios. Nurse Educ Today. 2001; 21(4):278-86.
20. Sá-Chaves I. Discutindo sobre portfólios nos processos de formação: entrevista com Idália Sá-Chaves. Olhar de Professor. 2004; 7(2):9-17. 21. McMullan M, Endacott R, Gray MA, Jasper $\mathrm{M}$, Miller CML, Scholes J, et al. Portfolios and assessment of competence: a review of the literature. J Adv Nurs. 2003; 41(3):283-94.

DOI: 10.1590/S1516-18462009005000036

RECEBIDO EM: 22/09/2008

ACEITO EM: 10/04/2009

Endereço para correspondência:

Regina Yu Shon Chun

Rua Coronel Quirino, 1835 ap. 71

Campinas - SP

CEP: 13025-003

E-mail: reginayu @fcm.unicamp.br

Rev. CEFAC. 2009 Out-Dez; 11(4):688-694 